\title{
FISCAL POLICY IN ENDOGENOUS ECONOMIC GROWTH MODELS WITH TWO R\&D SECTORS
}

\author{
Lecturer PhD Candidate Cosmin Enache, West University of Timisoara \\ cosmin.enache@feaa.uvt.ro
}

\begin{abstract}
This paper is intended to investigate the possibilities for government interventions based on fiscal policy measures in economies like those described in endogenous growth models with two $R / D$ sectors.
\end{abstract}

Keywords: fiscal policy, endogenous economic growth

JEL Codes: H30, E10, L16, O31, O40

\section{Introduction}

In Solow-Swan neoclassical model of economic growth the main determinant of long-term economic growth rate (in the steady state, on balanced growth path) is represented by technological change, which is an exogenous variable in the model. From a methodological point of view, treating technological change as an exogenous variable is just a simplifying assumption, which is not a realistic one. More, treating technological change as an exogenous variable makes useless any attempts of government authorities to influence the long-run economic growth rate. These two shortcomings determined a reconsideration of the technological change nature and therefore some attempts to introduce into the neoclassic growth model an additional relation in order to describe the evolution of the technological change as an endogenous variable.

The attempts to introduce the technological progress in the neoclassical production function with constant returns of scale as an additional input (together with physical capital and labor) were confronted wit a methodological difficulty represented by the fact that because of the constant returns of scale of the production functions, the inputs could not be paid their marginal product. These serious methodological difficulties were surpassed by dropping the neoclassical hypothesis of independence of technological progress from the individual decisions pf economic agents. The reckoning of the intentional nature of economic agents' decisions to invest in R\&D activities made possible the modeling of the technological progress as an endogenous variable.

As consequence, considering technological progress as endogenous removed one of the most unrealistic assumptions underlying the neoclassical growth models. Evidently, the technological progress is made as a result of the investments made by the economic agents and / or the individuals in their physical and human capital. Therefore, it was developed a new class of economic growth models that incorporate in their structure the technological progress as an endogenous variable, with strong links to the dimensions and the structure of markets, to competition and anti-trust policy and intellectual property rights protection policy - endogenous economic growth models.

Inside this new class of economic growth models one could distinguish two generations of models: a first generation composed by models for economies with one R\&D sector and a second generation composed by models for economies with two R\&D sectors.

In the first generation, a first group of economic growth models which incorporate the technological progress as an endogenous variable was developed using the analytical framework proposed by Paul Romer in his famous paper from 1990 . In his view, the technological progress is 
realized through innovations which are concretized in a new variety of capital that enters permanently in the production function of the final goods producers. The new product (or the new technology) resulting from innovation does not substitutes the products (or the technologies) already on the market, but is adding to these, contributing to expanding their variety. Therefore, this kind of technological progress leads to the horizontal differentiation of the products on the market. Endogenization of the technological progress in the proposed model is realized as a consequence of a fundamental hypothesis of the model: an innovation raises the general level of knowledge (in other words, it generates a non-excludable knowledge), that will determine a subsequent growth in the productivity of an R\&D activity.

A second group of economic growth models which incorporated the technological progress as an endogenous variable was developed later based on the theoretical foundations proposed in Grossman and Helpman (1991) and Aghion and Howitt (1992). Unlike Romer, these considered that innovations are concretized in a product, in a technology or in a new way of organizing the production which will replace older products, technologies or ways of organizing the production used for the final goods production. In this setting, a new innovation replaces one or more older innovations through the Schumpeterian process called "creative destruction". From a historical point of view, the technological progress is like a "quality ladder" of innovations. This kind of technological progress leads to vertical differentiation of the products. Endogenous technological progress was introduced having in mind that every innovation is realized using the stock of knowledge accumulated based on previous innovations. In these conditions, the technological progress is the result of inter-temporal external effects of innovation already made. In a metaphorical expression, every innovator stands ,on giants' shoulders”.

A third group of economic growth models that incorporate the technological progress as an endogenous variable was developed starting from the idea that both models already presented experience scale effects (the long term economic growth rate depends in an explicit manner on the population level), a feature that makes them unrealistic. Following this critique, Jones (1995) proposed a model that intended to eliminate the scale effects using a new technological knowledge accumulation function.

The second generation of endogenous growth models with two R\&D sectors is composed by two main groups of models: one that does not take into account the knowledge accumulation externalities between the two R\&D sectors (developed in Young (1998) ${ }^{1}$, Aghion and Howitt $(1998)^{2}$, Peretto $(1998)^{3}$ and Dinopoulos and Thompson $\left.(1999)^{4}\right)$ and one that takes into account these externalities (developed in $\mathrm{Li}(2000)^{5}$ and $\left.\mathrm{Li}(2002)^{6}\right)$.

\section{Theoretical foundations}

\subsection{Young model}

The idea that technological change is not realized only through new products innovations or only through quality improvements innovations was the foundation for a new class of endogenous growth models developed for economies with two R\&D sectors.

\footnotetext{
${ }^{1}$ Young A. - Growth Without Scale Effects, Journal of Political Economy, 106, (1), p. 41-63, 1998.

2 Aghion Ph., Howitt P. - Endogenous Growth Theory, MIT Press, Cambridge, Massachusetts, 1998, cap. 12, p. 403448 .

${ }^{3}$ Peretto P. - Technological Change and Population Growth, Journal of Economic Growth, December, 1998, 3, (4), p. 238-311, 1998.

${ }^{4}$ Dinopoulos E., Thompson P. - Scale Effects in Schumpeterian Models of Economic Growth, Journal of Evolutionary Economics, 9, (2), p. 157-185, 1999.

${ }^{5}$ Li C.-W. - Endogenous vs. Semi-Endogenous Growth in a Two-R\&D-Sector Model, Economic Journal, 110, (462), p. C109-C122, 2000.

${ }^{6}$ Li C.-W. - Growth and Scale Effects: The Role of Knowledge Spillovers, Economics Letters, 74, (2), p. 177-186, 2002.
} 
The economy described in these models is composed by three production sectors and two R\&D sectors.

In the three production sectors the economic agents produce three kinds of goods: a final good and two intermediate goods A and B. The production functions of these three kinds of goods have the following characteristics:

- the final good (Y) is produced using only type A intermediate goods, under following production function:

$$
\mathrm{Y}_{\mathrm{t}}=\left[\int_{0}^{\mathrm{A}_{\mathrm{t}}}\left(\mathrm{x}_{\mathrm{it}}^{\mathrm{a}}\right)^{\alpha} \mathrm{di}\right]^{\frac{1}{\alpha}}
$$

where:

$\mathrm{x}_{\mathrm{it}}^{\mathrm{a}} \quad$ - the quantity from type A intermediate good $\mathrm{i}$;

$\mathrm{A}_{\mathrm{t}} \quad$ - the number of type A intermediate goods;

$\alpha \quad$ - scalar coefficient.

- type A intermediate goods are produced using only type B intermediate goods, under following production function:

$$
\mathrm{x}_{\mathrm{it}}^{\mathrm{a}}=\mathrm{B}_{\mathrm{it}} \mathrm{x}_{\mathrm{it}}^{\mathrm{b}}
$$

where:

$\mathrm{x}_{\mathrm{it}}^{\mathrm{b}} \quad$ - the quantity from type B intermediate good $\mathrm{i}$;

$\mathrm{B}_{\text {it }} \quad$ - the quality level of type B intermediate good $\mathrm{i}$.

- type B intermediate goods are produced using only labor, under following production function:

$$
x_{i t}^{b}=(1-b) \frac{(1-a) L_{t}}{A_{t}}
$$

where:

b - the proportion of work force available after the employment in A R\&D sector engaged in final good production.

The two R\&D sectors engage in different R\&D activities:

- in the first R\&D sector, innovations consist in new type A intermediate goods. Knowledge accumulations is realized after the following relation:

$$
\dot{\mathrm{A}}_{\mathrm{t}}=\mathrm{aL}_{\mathrm{t}}
$$

where:

$\mathrm{a} \in(0,1) \quad$ - the proportion of total work force employed in type A R\&D sector.

- in the second R\&D sector are carried out activities that are oriented to innovations consisting in quality improvements of type B intermediate goods. Knowledge accumulations in this sector is realized after the following relation 


$$
\dot{\mathrm{B}}_{\mathrm{it}}=\delta \mathrm{b} \frac{(1-\mathrm{a}) \mathrm{L}_{\mathrm{t}}}{\mathrm{A}_{\mathrm{t}}} \mathrm{B}_{\mathrm{t}}
$$

where:

$\delta \quad$ - the productivity of the R\&D activities.

In this model it could be proved that, in equilibrium, the growth rate of output per capita $\left(g_{y}\right)$ depends on type A knowledge accumulation rate $\left(\mathrm{g}_{\mathrm{A}}\right)$ and on type B knowledge accumulation rate $\mathrm{B}\left(\mathrm{g}_{\mathrm{B}}\right)$, according to the following relation:

$$
\mathrm{g}_{\mathrm{y}}=\frac{1-\alpha}{\alpha} \mathrm{g}_{\mathrm{A}}+\mathrm{g}_{\mathrm{B}}
$$

On the balanced growth path, the two knowledge accumulation rates should be constant. Type A knowledge accumulation rate $\left(\mathrm{g}_{\mathrm{A}}\right)$ could be derived using relation (4):

$$
\mathrm{g}_{\mathrm{A}}=\mathrm{a} \frac{\mathrm{L}_{\mathrm{t}}}{\mathrm{A}_{\mathrm{t}}}=\mathrm{n}
$$

Type B knowledge accumulation rate $\left(\mathrm{g}_{\mathrm{B}}\right)$ could be derived using relation (5):

$$
g_{B}=\delta b \frac{(1-a) L_{t}}{A_{t}}=\delta b \frac{(1-a) n}{a}
$$

Having in mind the last two relations, the relation of output per capita growth rate becomes:

$$
g_{y}=\frac{1-\alpha}{\alpha} n+\delta b \frac{(1-a) n}{a}
$$

As it could be noticed, the output per capita growth rate depends on the population growth rate (n), on allocations of labor between the two sectors (the coefficients a and b) and on R\&D productivity coefficient $(\delta)$.

\subsection{Li model}

The model is built on Young model already presented. The difference consists in the introduction in the model of some positive externalities between the two R\&D sectors of the economy. These positive externalities will influence the knowledge accumulation process in the two $\mathrm{R} \& \mathrm{D}$ sectors of the economy.

Knowledge accumulation in type A R\&D sector is realized following the relation:

$$
\dot{\mathrm{A}}_{\mathrm{t}}=\mathrm{aL}_{\mathrm{t}} \kappa_{\mathrm{t}}^{\mathrm{A}}
$$

where:

$\kappa_{\mathrm{t}}^{\mathrm{A}} \quad$ - a term that quantifies the positive externality in type A R\&D sector. 
This positive externality in type A R\&D sector is due both to the knowledge accumulated in this sector and to the knowledge accumulated in type B R\&D sector. The relation of this externality is the following:

$$
\kappa_{t}^{A}=\frac{A_{t}^{\phi_{A}} B_{t}^{\eta_{A}}}{B_{t}}
$$

where:

$A_{t}^{\phi_{A}}$ - positive externality between type A R\&D activities;

$\phi_{\mathrm{A}} \quad$ - positive scalar coefficient;

$B_{t}^{\eta_{A}}$ - positive externality determined by the type B R\&D activities;

$\eta_{\mathrm{A}} \quad$ - positive scalar coefficient.

In type B R\&D sector, knowledge accumulation is realized following the relation:

$$
\dot{\mathrm{B}}_{\mathrm{it}}=\delta \mathrm{b} \frac{(1-\mathrm{a}) \mathrm{L}_{\mathrm{t}}}{\mathrm{A}_{\mathrm{t}}} \kappa_{\mathrm{t}}^{\mathrm{B}}
$$

where:

$\kappa_{\mathrm{t}}^{\mathrm{B}} \quad-$ a term that quantifies the positive externality in type B R\&D sector.

This positive externality in type B R\&D sector is due both to the knowledge accumulated in this sector and to the knowledge accumulated in type A R\&D sector. The relation of this externality is the following:

$$
\kappa_{t}^{B}=A_{t}^{\eta_{B}} B_{t}^{\phi_{A}}
$$

where:

$A_{t}^{\eta_{B}}$ - positive externality determined by the type A R\&D activities;

$\eta_{\mathrm{B}} \quad$ - positive scalar coefficient;

$\mathrm{B}_{\mathrm{t}}^{\phi_{\mathrm{B}}} \quad$ - positive externality between type B R\&D activities;

$\phi_{\mathrm{B}} \quad$ - positive scalar coefficient.

Type A knowledge accumulation rate $\left(g_{A}\right)$ could be derived from relation (10):

$$
g_{A}=a \frac{L_{t}}{A^{1-\phi_{A}} B^{1-\eta_{A}}}
$$

Type B knowledge accumulation rate $\left(\mathrm{g}_{\mathrm{B}}\right)$ could be derived from relation (12):

$$
g_{B}=\delta b(1-a) \frac{L_{t}}{A^{1-\eta_{B}} B^{1-\phi_{B}}}
$$

On the balanced growth path, knowledge accumulation rates in the two R\&D sectors should be constant. This implies that the following two conditions should stand: 


$$
\begin{aligned}
& \mathrm{n}=\left(1-\phi_{\mathrm{A}}\right) \mathrm{g}_{\mathrm{A}}+\left(1-\eta_{\mathrm{A}}\right) \mathrm{g}_{\mathrm{B}} \\
& \mathrm{n}=\left(1-\eta_{\mathrm{B}}\right) \mathrm{g}_{\mathrm{A}}+\left(1-\phi_{\mathrm{B}}\right) \mathrm{g}_{\mathrm{B}}
\end{aligned}
$$

The above two conditions form a two equations system with two unknowns. If the two ecquations are linearly independent, their equation system has a unique solution, given by:

$$
\begin{aligned}
& \mathrm{g}_{\mathrm{A}}=\frac{\eta_{\mathrm{A}}-\phi_{\mathrm{B}}}{\mathrm{D}} \mathrm{n} \\
& \mathrm{g}_{\mathrm{B}}=\frac{\eta_{\mathrm{B}}-\phi \mathrm{A}}{\mathrm{D}} \mathrm{n}
\end{aligned}
$$

where:

$D=\left(1-\phi_{A}\right)\left(1-\phi_{B}\right)-\left(1-\eta_{A}\right)\left(1-\eta_{B}\right)-$ determinant of the coefficient matrix.

In this case, technological knowledge accumulation rates in the two R\&D sectors $\left(g_{A}\right.$ and $\left.g_{B}\right)$, and therefore the output per capita growth rate $\left(g_{y}\right)$ are all determined solely by the population growth rate and by the size of intra and inter-sectoral externalities given by parameters $\left(\phi_{\mathrm{A}}, \phi_{\mathrm{B}}, \eta_{\mathrm{A}}, \eta_{\mathrm{B}}\right)$. All these variables could not be influenced by the public policies, fact which gives a semi-endogenous character to the model.

Also, it should be stated that, if the equation composing the system in (16) and (17) are linearly dependent, this requires the following restrictions:

$$
\begin{gathered}
\phi=\phi_{\mathrm{A}}=\eta_{\mathrm{B}} \\
\eta=\eta_{\mathrm{A}}=\phi_{\mathrm{B}}
\end{gathered}
$$

These restrictions transform the equation system in (16) and (17) into a single equation:

$$
\mathrm{n}=(1-\phi) \mathrm{g}_{\mathrm{A}}+(1-\eta) \mathrm{g}_{\mathrm{B}}
$$

Because this is an equation with two unknowns, it is obvious that a solution could be given only if another equation is included in the model, with the same two unknowns. This extension of the model will make the two knowledge growth rates to depend on variables which could be influenced through public policies.

\section{Fiscal policy implications}

Because in the economies described in models like those already presented the markets are not competitive (on the one hand, the innovating economic agents in the two R\&D sectors become monopolists after they patent their invention, and on the other hand, the economic agents that produce intermediate goods become monopolists after they buy the patent from the R\&D sector) this generates inefficiency at the whole economy level. Therefore, long-term economic growth rate obtained in the models will be lower than the one that ensures the social optimum. This shows that there are possible some Pareto improvements through government intervention. 
From a general point of view, in economies like those described in the presented models, the government interventions through fiscal policy measures could be oriented in three main directions:

- a subsidy financed through a lump-sum tax (in order not to induce distortions) for the intermediate goods production will determine the producers of the final good to pay for these intermediates a price closer to (or, if the subsidy has an appropriate measure, equal to) the marginal cost. This reduction of the intermediate goods' price will determine a corresponding increase in demand, which will determine in turn a subsequent increase in the intermediate goods' production that will close it to its social optimal level.

- a subsidy financed through a lump-sum tax (in order not to induce distortions) for the final good production will determine a such a reduction of the production costs that will compensate the loss accrued from the acquisition of the intermediate goods at monopoly prices, greater that their marginal cost.

- a subsidy financed through a lump-sum tax (in order not to induce distortions) for financing $\mathrm{R} \& \mathrm{D}$ activities will lead to lower $\mathrm{R} \& \mathrm{D}$ costs, and therefore, will determine an increase of the present value of the future flows of profits obtainable form $R \& D$ activities. This will close the private value of innovations to their social value. Anyway, this kind of fiscal policy measure does not eliminate entirely the inefficiency at the economy level because the monopolists from the intermediate goods sector will produce and offer on the market a quantity of these goods below the one that ensure the social optimum.

All these fiscal policy measures could be applied in an economy like the one described in the Young model, because the long-run economic growth rate depends on the labor allocation between the two R\&D sectors (parameters a and b). Moreover, another determinant of long-term economic growth rate is represented by productivity of the $R \& D$ activities. This determinant is affected by its nature to uncertainty. If we accept the idea that R\&D activities' productivity is influenced not only by the quantity of labor employed in these activities (the parameters a and b) but also by the quality of labor (human capital), than public expenditures on education, and especially on higher education, could drive economic growth through raising the individuals' incentives to invest in their human capital. But, the positive effects of public expenditures on education on human capital accumulation are not instantaneous and are produced with a time lag.

In the Li model, in the situation in which the relations that form the equation system in (16) and (17) are linearly independent, the obtained solutions for the technological knowledge accumulation in the two R\&D sectors show that the long-run economic growth rate depends only on the parameters which quantify the intra and inter-sectoral external effects of knowledge accumulation, parameters which could not be influenced through fiscal policy measures. In the situation in which the relations composing the system in (16) and (17) are linearly dependent it is necessary to introduce a new equation in the model in order to obtain a two equations system with two unknowns that cold be solved. Because this new relation could be represented by the consumers' preferences or by profit maximization of R\&D economic agents or by profit maximization of productive economic agents, will surely introduce in the relations for the technological knowledge accumulation some variables which could be influenced through fiscal policy measures. In this case, the same fiscal policy measures are appropriate as in the Young model.

\section{References:}

1. Aghion Ph., Howitt P. - A Model of Growth Through Creative Destruction, Econometrica, vol. 60, no. 2, March, p. 323-351, 1992.

2. Aghion Ph., Howitt P. - Endogenous Growth Theory, MIT Press, Cambridge, Massachusetts, 1998, cap. 12, p. 403-448.

3. Dinopoulos E., Thompson P. - Scale Effects in Schumpeterian Models of Economic Growth, Journal of Evolutionary Economics, 9, (2), p. 157-185, 1999. 
4. Grossman G. M., Helpman E. - Quality Ladders in the Theory of Growth, Review of Economic Studies, 58, p. 43-61, 1991.

5. Jones C. I. - R\&D-Based Models of Economic Growth, Journal of Political Economy, August, 103, p. 759-784, 1995.

6. Li C.-W. - Endogenous vs. Semi-Endogenous Growth in a Two-R\&D-Sector Model, Economic Journal, 110, (462), p. C109-C122, 2000.

7. Li C.-W. - Growth and Scale Effects: The Role of Knowledge Spillovers, Economics Letters, 74, (2), p. 177-186, 2002.

8. Peretto P. - Technological Change and Population Growth, Journal of Economic Growth, December, 1998, 3, (4), p. 238-311, 1998.

9. Romer P. M. - Endogenous Technological Change, The Journal of Political Economy, vol. 98, Part 2: The Problem of Development: A Conference of the Institute for the Study of Free Entreprise Systems, October, p. S71-S102, 1990.

10. Young A. - Growth without Scale Effects, Journal of Political Economy, 106, (1), p. 4163, 1998. 